\title{
EDUCAÇÃO ESCOLAR INDÍGENA: UM MODO PRÓPRIO DE RECRIAR A ESCOLA NAS ALDEIAS GUARANI
}

\author{
Maria Aparecida Bergamaschi
}

\begin{abstract}
RESUMO: A educação escolar específica e diferenciada vem sendo constituída pelos povos indígenas brasileiros, com maior intensidade, nas últimas décadas. Os Guarani, zelosos de sua cosmologia e contrários à introdução de aparatos ocidentais em seu modo de vida tradicional, foram historicamente desfavoráveis à escola. Hoje, algumas aldeias buscam-na, como uma forma de se aparelharem para compreender o "mundo dos brancos", acessando, por meio da escola, conhecimentos necessários para uma interação mais simétrica com a sociedade não-indígena. A reflexão proposta neste texto aborda os processos de escolarização, evidenciando as formas de apropriação que ocorrem na escola das aldeias Guarani, no Rio Grande do Sul, por meio de práticas escolares que buscam constituir um modo próprio de ensinar, em diálogo com os princípios que compõem a educação tradicional e a cosmologia desse povo.
\end{abstract}

Palavras-chave: Educação indígena. Escolas indígenas. Escolas Guarani.

\section{INDIGENOUS SCHOOL EDUCATION:}

A PARTICULAR WAY OF RECREATING SCHOOL IN GUARANI VILLAGES

ABSTRACT: The constitution of a specific and differentiated school education by Brazilian indigenous peoples has become more intensive in the last decades. Concerned about their cosmology and contrary to the introduction of Western instruments in their traditional way of life, the Guarani have historically been against school. Nowadays, some of their villages look for it as a way to provide themselves with tools to understand the "white man's world" and gain access to

Doutora em Educação e professora na Faculdade de Educação da Universidade Federal do Rio Grande do Sul (UFRGS). E-mail: cidabergamaschi@terra.com.br 
Educação escolar indígena: um modo próprio de recriar a escola nas aldeias Guarani

the necessary knowledge to have a more symmetrical interaction with the non-indigenous society. The reflection proposed in this text approaches school enrollment processes and pinpoints ways of appropriation that occur in the Guarani village schools, in the State of Rio Grande do Sul, through school practices that aim to constitute their own way of teaching in a dialogue with the principles that make up the traditional education and cosmology of this people.

Key words: Indigenous education. Indigenous schools. Guarani schools.

\section{Introdução: um outro modo de fazer a escola nas aldeias?}

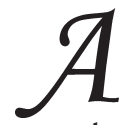

$s$ crianças chegam aos poucos. Meninas sentam de um lado da sala, meninos de outro. Algumas, menores, sentam-se em volta da mesa do professor. As mesas e cadeiras estão todas voltadas para o quadroverde, onde estão escritos dois textos na língua Guarani (...). Aos poucos chegam mais crianças que, suavemente, integram-se ao trabalho. Um adulto entra na sala, acompanhando seus filhos, arruma duas cadeiras, acomoda-os e sai, sem causar interrupção (...). A sala está repleta: 22 crianças sentadas. Duas, bem pequenas, acompanham de pé o desenho dos irmãos maiores. Nesse momento, na sala de aula, as idades variam de 3 a 13 anos (...). Há uma vivacidade em cada um, nos olhos, no corpo que não se anula entre as classes. Se sentem vontade de sair, saem sem pedir autorização, logo retornam. Os passos são imperceptíveis. Lembro-me das palavras de Jakupé: "Guarani toca a terra, acaricia o solo". É assim que caminham, com suavidade, tocando e acariciando o solo, ou mesmo o assoalho de madeira do galpão onde funciona a escola. Entre eles há uma proximidade amorosa: não falam alto, não brigam, não há necessidade de o professor chamar a atenção. Estão concentrados em seus desenhos que, segundo o professor, referem-se ao que fizeram hoje, ao que sonharam, ao que está em sua imaginação. A maioria deles desenha elementos da natureza: árvores, rios, peixes, nuvens - em todos os desenhos aparece um sol, o Kuaraí, e alguns estão acompanhados de palavras, em Guarani (...). A vida do interior da sala de aula é muito próxima à vida de fora: as pessoas passam, conversam com o professor através da janela, um cachorro fica sentado ao lado da classe de um menino. Algumas crianças saem, retornam. O professor não pressiona, não "aperta", diriam eles (...). A aula termina quando termina o envolvimento com a atividade. (Diário de Campo, 14 jul. 2004)

Essa cena, registrada no Diário de Campo, retrata uma das inúmeras atividades escolares que acompanhei nas aldeias do Cantagalo e 
da Lomba do Pinheiro e mostra a escola que está sendo construída pelos Guarani, desde sua cosmologia, desde suas concepçôes de mundo. "É muito difícil fazer uma escola diferenciada", frase que unifica as vozes dos professores indígenas nos encontros promovidos pela Secretaria de Estado da Educação e com a qual concordo, pois é reconhecida a força homogeneizadora de uma instituição constituída no seio da cosmologia ocidental moderna. Porém, práticas como a relatada mostram a força silenciosa que perpassa a escola, se fazendo na aldeia, anunciando possibilidades para um outro fazer escolar, desde outra forma de estar no mundo.

É no dia-a-dia, marcado pela cosmologia indígena, que uma escola diferenciada aparece nos pequenos, porém potentes indícios que apontam outro modo do fazer escolar. Nessa perspectiva, os sentidos da escola vão-se constituindo em atos, ao se apropriarem os indígenas de um aparelho educativo que não nasceu no interior de suas antigas tradiçôes, mas que, ao ser trazido para dentro da aldeia, é conferido de significados próprios. ${ }^{1}$ Os sentidos que atribuem à escola se constituem a partir de um modo próprio de colocar em prática determinados preceitos escolares e que, ao serem praticados na escola da aldeia, assumem outra conotação, como já anunciava Aracy Lopes da Silva (2001, p. 106):

Entre o significado da escola como produto histórico do Ocidente como instituição destinada, entre outras coisas, também a "vigiar e punir" - e o interesse dos povos indígenas pela escrita, pela cultura universal, pela tecnologia e mesmo pela escola, deve estar o espaço para a criação de novos perfis e sentidos para essa instituição, gerados por seu processamento intelectual e social em contextos indígenas.

A reflexão que ora inicio, apresentando cenas da escola Guarani, está assentada no trabalho que realizo junto a duas aldeias, no Rio Grande do Sul, ${ }^{2}$ acompanhando o movimento de constituição da escola. A aldeia da Lomba do Pinheiro, que para os Guarani é a Tekoá Anhetenguá, é composta por doze famílias nucleares, configurando uma população de setenta e cinco pessoas, sendo que a maior parte é proveniente da Argentina, num movimento de reapropriação das terras ancestrais situadas a leste da região do sul da América. Todas as pessoas da Tekoá Anhetenguá são falantes do idioma Guarani, reconhecido por eles como Mbyá. E uma pequena área, que, na sua origem, se destinava a um 
Educação escolar indígena: um modo próprio de recriar a escola nas aldeias Guarani

local de passagem, estando longe de oferecer as condições adequadas para uma Tekoá nos moldes tradicionais. Porém, mesmo "apertados", como dizem de si no contato com a sociedade não-indígena, mantêm uma pequena mata, plantam milho, mandioca, batata-doce e amendoim e esforçam-se para manter vivo o modo de ser Guarani, realizando seus rituais na $O p y$, casa de reza cujo acesso está restrito às pessoas Guarani.

Mesmo que na memória coletiva a escola figure como um aparato da cultura ocidental, cuja imposição motivou a saída de Missiones, na Argentina, conforme relatam os moradores atuais da aldeia, nos últimos três anos a escola está em processo de implantação. Não há um prédio específico para a escola, que, em seu curto tempo de existência, já funcionou em distintos lugares. Está assentada agora numa casa construída para sediar o centro comunitário. O professor Guarani, indicado pelas lideranças tradicionais da aldeia, reúne-se em torno de vinte crianças e profere as aulas quase que exclusivamente na sua língua materna. Com o auxílio de professoras ligadas à Universidade Federal do Rio Grande do Sul, desenvolvem também, na aldeia, aulas para um grupo de pessoas adultas, que evidenciou o desejo de aprender a falar português, a ler e escrever, a fim de dar conta do contato constante com a cidade.

A aldeia do Cantagalo, cujo nome em Guarani é Tekoá Jataity, é composta por vinte e duas famílias e ocupa uma área de 246 hectares de terra já demarcados. Em geral, as famílias fazem uma pequena roça, porém o contato com a cidade é permanente, dada a proximidade. Além de afluírem ao centro para a venda de artesanato e freqüentarem instituiçōes responsáveis pelas políticas públicas indigenistas, recebem visitas constantes de pessoas e instituiçôes não-indígenas. A escola, em funcionamento desde o ano de 2000, ainda não conta com um prédio específico, o que faz com que funcione em espaços alternativos, como na casa do professor, ou numa construção que abrigava o antigo posto de saúde e, atualmente, num galpão de madeira.

São dois professores Guarani que atuam na escola, ambos indicados pela comunidade. Porém, reconhecem que a $O p y$ é a sua universidade, sendo que consideram as pessoas mais velhas as suas bibliotecas, pois são elas que, como guardiōes da memória, detêm os saberes ancestrais e têm a responsabilidade de transmiti-los às novas geraçóes. 
Duas vezes por semana, recebem uma professora não-indígena, contratada pela Secretaria de Estado da Educação para ensinar os adultos, especialmente escrita e leitura e a língua portuguesa, ferramentas que consideram importantes para o contato com o "mundo dos brancos", como se referem às sociedades não-indígenas que envolvem a aldeia.

Escola imposta pelo colonizador. Mesmo transformada historicamente pela ação de centenas de etnias, tendo tutelado os povos indígenas e atrelado às práticas escolares valores do Estado brasileiro, a escola nas aldeias apresenta possibilidades para o protagonismo indígena, especialmente amparada pelo aparato legal que criou a Escola Específica e Diferenciada. Embasada numa legislação própria, produto da participação organizada dos povos indígenas nessas últimas décadas, abre caminhos para a escola indígena que, processualmente, é assumida pelas aldeias e aponta possibilidades de práticas baseadas na cosmologia de cada povo. Observando atentamente a vida na aldeia e as atividades desenvolvidas na escola, aparece, aos poucos, a força criadora de outros modos do dizer e do fazer escolar.

\section{A educação tradicional nas aldeias Guarani}

A cosmovisão xamânica Guarani considera a sociedade como um todo, em que a educação não se separa, espacial e temporalmente, das demais práticas. A educação não se restringe à $O p y$ e, tampouco, aos conhecimentos escolares. "Escola é toda a vida do Guarani", disse André, quando perguntei se a $O p y$ correspondia à escola. Mostram-se ambíguos em relação à instituição escolar que começa a ser implementada em algumas aldeias, fato que compreendo como cuidado com seu modo de vida, o Nhande Reko. Resistem em aderir à educação escolar, pois é uma possibilidade concreta de se exporem a um saber parcelado, fragmentado que, além de colocar o conhecimento ocidental como único, elege a escola como espaço e tempo únicos de educação.

A cosmologia dos povos indígenas não é estática, tampouco essencialista e pura, pois, como todas as sociedades, os Guarani também se modificam, se reinventam a todo o momento e saberão se reinventar diante de novos acontecimentos, entre eles a escola, como já estão fazendo. Contudo, temos que reconhecer o poder homogeneizador da instituição escolar, especialmente no que tange a instaurar tempos e 
Educação escolar indígena: um modo próprio de recriar a escola nas aldeias Guarani

espaços únicos, igualmente impondo saberes ocidentais como verdades absolutas. É com isso que se preocupam os Guarani, diante da possibilidade de terem sua forma tradicional de educação fragilizada, desvalorizada, pois a entendem como integral e integrada ao seu modo de ser, composta por um conjunto de preceitos e práticas responsáveis pela constituição da pessoa Guarani.

Predominam, entre os Guarani, duas formas de aprender. Uma está ligada ao esforço pessoal: é a busca, desencadeada pela curiosidade que se desenvolve na pessoa, desde pequena. A outra é revelação e se relaciona à primeira, pois, para receber a revelação das divindades, a pessoa também faz um esforço para viver de acordo com o Nhande Reko. Conhecimento, para os Guarani, é expresso por meio da palavra Arandu: ara significa tempo, dia; ñendu quer dizer sentir, experimentar. Nessa perspectiva, Arandu significa sentir o tempo, fazer o tempo agir na pessoa. As duas formas de aprender acima mencionadas estão ligadas ao tempo e, por isso, quanto mais velha, a tendência é ser a pessoa mais sábia e, conseqüentemente, mais respeitada por todos. "Os velhos são nossas bibliotecas", disse o professor Marcos, da aldeia Cantagalo, referindo-se às pesquisas que vêm realizando acerca dos saberes tradicionais, nas quais as pessoas velhas são suas fontes de consulta. Para os Guarani, o conhecimento está acontecendo na busca de cada um junto aos mais velhos e numa sábia escuta da revelação.

Observando atentamente as características da educação tradicional Guarani, tento compreendê-las a partir de sua cosmologia, sublinhadas como marcas que sobressaem ao olhar e que, a meu ver, devem ser consideradas ao se pensar e praticar a escola de inspiração ocidental dentro da aldeia. Acompanhando as crianças em seu fazer diário, aparece, nos belos e expressivos olhos negros, a curiosidade, que busca apreender o mundo, descobri-lo para si: desde a forma de estender um pano para sentar-se e brincar sobre ele, imitando as mães que costumam sentar-se ao chão, sobre uma colcha, até os passos ritmados da dança e do cântico que acompanham os movimentos corporais durante os rituais ou as apresentaçôes dos corais. "Para aprender tem que perguntar", repetia várias vezes o professor Alberto, quando indagado sobre como ocorre a aprendizagem na perspectiva Guarani, pressupondo a curiosidade que move a pessoa em direção à pergunta.

$\mathrm{O}$ aprender, acionado pela curiosidade, privilegia a observação, o que configura um traço sobressalente e que busca no fazer, muito mais 
do que no dizer, possibilidades concretas para a aprendizagem. A pessoa é, desde pequena, uma observadora da natureza, da qual se sente parte, tendo-a como fonte inspiradora de vida e de educação, mas é também uma observadora do comportamento de outras pessoas. Especialmente os pequenos têm nos irmãos maiores e nos adultos seus parâmetros e, por meio da imitação, constroem seus comportamentos particulares. Nesse sentido, desde pequena, a pessoa observa, inspirando-se naquilo que a rodeia, tendo como exemplo as imagens que estão a sua disposição, buscando assemelhar-se ao outro e, a partir daí, constituir um comportamento próprio, que também o distinga. Imitam nas brincadeiras e nas demais situaçôes da vida, pois acompanham os adultos nas mais diferentes atividades.

Nessa perspectiva, as crianças Guarani desenvolvem-se a partir dos modelos que observam, imitando e, principalmente, fazendo. Usando uma categoria cara e de difícil concretização nos processos educativos ocidentais, realço como característica da educação dos kyringue a autonomia, que expressa a individualidade da pessoa, não como individualismo que a isola e afasta das demais, mas como reconhecimento de cada um no coletivo. São situaçôes concretas que revelam uma forma de estar no mundo e de se dispor a ele, desde o nascimento, quando o corpo se abriga na carinhosa contigüidade propiciada pela proximidade amorosa do colo da mãe e na comunicação corporal que se estabelece nas brincadeiras, nas danças, no contato com irmãos e outras crianças do grupo familiar - com o pai, com os avós e demais parentes -, mas que fazem sobressair, também, o quanto cada pessoa deve, desde pequena, responsabilizar-se de si.

Destaco também a oralidade, presente não apenas na fala, mas na escuta respeitosa e atenta à palavra: escutar e entoar os cantos e se dispor ao ensinamento que é oferecido pela palavra são marcas importantes da educação tradicional Guarani. Reconheço, também, que o aprender, mais do que o ensinar, está intensamente presente na vida das crianças e das pessoas em geral, sendo essa uma postura necessária para se tornar Guarani de verdade. "Aprendi por mim, pela minha cabeça”, repetem quando perguntados sobre como aprenderam determinadas coisas, explicitando o movimento de busca e de autonomia presente nessa expressão.

E, como anúncio inicial que propus, ao evidenciar alguns pressupostos, destaco o respeito, atitude sempre evocada quando o assunto 
Educação escolar indígena: um modo próprio de recriar a escola nas aldeias Guarani

é educação tradicional. E não me refiro apenas ao respeito às pessoas mais velhas, qualidade reconhecida nos povos indígenas brasileiros, mas o respeito a cada pessoa na sua individualidade, na forma de expressão de si e na busca do conhecimento e dos seus limites, o que faz com que os adultos não repreendam as crianças, mas as observem e as acolham em suas características próprias que vão, aos poucos, consolidando cada pessoa Guarani. Essas características, que são presenças fortes na educação tradicional dos Guarani e que aparecem no cotidiano, estão inseridas no Nhande Reko, como afira Laricq (1993, p. 105):

Todas las formas de esta educación están finalmente entretejidas con la práctica social circundante. De allí que sea imposible mantener categorías y comportamientos asociados, de alguna forma alejados de ella. No existen aquí espacios sociales dedicados a la transmisión, creación o rectificación de comportamientos y categorías más que los escenarios mismos de la vida y las actividades que la producen y reproducen. La existencia del monte, la participación comunitaria en el ritual, la ingestión de determinado tipo de alimentos y las consecuencias físicosociales de esto, no podrán ser enseñados como valores en abstracto, porque la acción motivará la enseñanza y la comprobación de su efectividad la harán verdadera.

E são esses pressupostos que embasam uma outra forma de pensar e fazer a escola, sustentada pela confiança que cada aldeia deposita no seu modo próprio de educar.

\section{A escola e a educação tradicional: encontro de cosmologias}

"Guarani tem o seu sistema de educação, não é separado, está tudo junto. Tem a $O p y$ e se ensina tudo junto", advertiu José Cirilo, por ocasião de nosso primeiro encontro na aldeia para falar da escola que estavam cogitando solicitar à Secretaria de Estado de Educação. Ao afirmar a educação do povo Guarani, o cacique da Tekoá Anhetenguá fez questão de frisar o seu conhecimento de outra forma de educação, uma educação "separada", alheia a sua cosmologia. O cacique está aludindo à sociedade ocidental moderna, que tem na escola uma forte referência para as práticas educativas. Falando do sistema Guarani, o cacique explicita um entendimento global da sociedade e do mundo, entendimento que encontra ressonância em Balandier (1997, p. 156), quando diz que, nas sociedades tradicionais, a ordem social e a ordem 
cósmica são indissociáveis e equivalentes e as "teorias do mundo, do homem e da sociedade são globais, unificadoras". O saber, acessível a todos, "é dividido a partir de graus de iniciação que o eleva, e não a partir de uma setorização de conhecimentos”, que o fragmenta. O modo de ser Guarani, como totalidade cósmica, estranha a setorização e a disciplinarização que marcam o conhecimento e as instituições ocidentais da modernidade.

A afirmação persistente dos Guarani, repetindo que a escola, mesmo funcionando em suas aldeias, é de "branco", deixa subentendido que a compreendem como constituída e constituidora de uma outra concepção de mundo, de uma outra ordem, a ordem ocidental. Essa ordem é resultante "de la trama milenar tejida por ese trigno cosmológico", a saber: "helênica, cristiana y moderna" (Dorneles, 1996 , p. 62). Não só a escola é resultante desse processo, mas a força que propulsionou a conquista e colonização do Novo Mundo pela Europa se deu justo no cruzamento das concepçóes de mundo medieval cristã e moderna renascentista, idéias que passaram a conviver, modificando-se mutuamente. A Europa renascentista, impulsionada pelas marcas evocadas no passado helênico, construiu os primeiros indícios do pensamento científico que caracterizam a modernidade ocidental.

No interior da cosmologia ocidental moderna, inspirada na ciência que ordena o mundo e fragmenta o conhecimento, constitui-se a escola como um projeto educativo para a formação do cidadão, com uma identidade nacional. Diz Elias (1994) que o controle do indivíduo, na sociedade moderna, saiu das mãos das tribos, das paróquias, dos feudos e guildas e transferiu-se para um Estado centralizado e urbano. A sociedade, mais complexa e especializada, implementou formas de segregação espacial e temporal, particularmente das crianças e jovens, tornando a trajetória educativa cada vez mais longa e complicada, distanciada da família e do trabalho. A escola, assentada numa verdade supostamente universal da ciência e da razão, no cristianismo e no conhecimento disciplinar, com o tempo, passou a ser obrigatória, expandindo-se para propagar o processo civilizador, desencadeado a partir da Europa. A idéia de escola como lócus específico e único de educação adquiriu universalidade e naturalizou-se. A sociedade ocidental moderna tornou-se escolarizada.

Contudo, a escola, assim como expressa, também elabora concepções de mundo, interagindo com o contexto histórico que habita. 
Educação escolar indígena: um modo próprio de recriar a escola nas aldeias Guarani

Para uma cosmologia que repousa na razão e na ciência, a escola da modernidade ocidental também passou a ser um mecanismo de ordenamento da sociedade, classificando, organizando linear e progressivamente as coisas e os acontecimentos, colocando-os em determinados compartimentos. É dessa concepção de educação separada, gerada por outra concepção de mundo, que fala José Cirilo, quando abre a discussão sobre a implementação da educação escolar na Tekoá Anhetenguá, onde é cacique. Mostra seu entendimento de que a escola é esse outro mundo, essa outra cosmologia que adentra no Nhande Reko e, estrategicamente, deixa registradas as diferenças entre as duas formas de viver e de educar. No entanto, não prescindem da escola, como evidenciam as palavras que seguem:

Antes não precisava de escola nem de posto de saúde. Hoje temos escola e posto de saúde (...). Hoje nós precisamos de escola porque muitas vezes as coisas dos brancos são decididas no papel escrito. Muitos de nós não sabemos ler nem escrever. Talvez por isso a escola seja um caminho que possa manejar todos esses conhecimentos além da escrita e, também, para buscar os nossos direitos (...). Hoje eu preciso de escola porque eu penso para o futuro dos meus filhos. Quando eles crescerem não quero que eles fiquem que nem eu, sem saber falar e sem entender. Isso eu não quero para eles. Por isso, quero que tenha uma escola dentro da aldeia, para ensinar a ler e escrever e para defender os direitos da comunidade e defender os mais velhos. (Alexandre Acosta, 60 anos. Depoimento gravado na aldeia Cantagalo, no dia 28 jan. 2004. Tradução Marcos Moreira)

Compreendo o que dizem os Guarani a respeito da importância da escola e da leitura-escrita-fala em português que a ela relacionam, dimensionando o quanto são demandados a decifrar as cidades, as instituições ocidentais com sua gigantesca burocracia. Em seu uso cotidiano, não mensuramos o quanto a escrita se insere nas relações pessoais e institucionais e, tampouco, nos questionamos sobre como é entendida ou como se entrepõe na vida e nas relações das diversas gradações de letramento que convivem em nossa sociedade. É a essa forte presença da escritura em sua vida que os Guarani se referem: para existir, o nome escrito, inscrito no documento; para viajar, o documento e o bilhete da passagem, adquirido; para transitar na cidade, ter cidadania, saber ler, decifrar o enigma da escrita, saber do sistema monetário; para comprar, dominar um conhecimento específico de consumo. 
Atentas ao movimento e zelosas de sua cultura, as lideranças das aldeias Guarani mostram suas preocupaçōes em "levar com cuidado" o processo de escolarização de seu povo, nas inúmeras indagações que dirigem a si próprios. Por que o Guarani quer escola? Para que serve a escola? Por que precisamos de escola? Para ler e escrever ou para quê? $\mathrm{O}$ que vai trazer para nossos filhos? Como é essa escola diferenciada? O que a escola vai trazer para a aldeia? Como vai ser daqui a dez anos? Até onde vai essa escola? Quais as regras que pautarão a vida dentro da escola? O que a escola vai ensinar?

É importante ler e escrever, ajuda na relação com os brancos. Isso não faz deixar pra trás a cultura do Guarani, por isso cada mãe e cada pai continuam ensinando. Eu quero melhorar a vida para meus filhos, com a escola que ensine como andar na cidade, ler as coisas, andar de ônibus, ler a placa. Para a luta do povo Guarani precisa escola. A fala, a memória não vai se perder. Guarani guarda as coisas na memória e não no papel, por isso daqui a dez anos eles sabem porque guardam na cabeça. (Fala de Teófilo, registrada no Diário de Campo, em 20 fev. 2004)

\section{Práticas escolares na aldeia}

Descrevo a escola na aldeia, chamando atenção para seu funcionamento, que foge à regularidade que conforma tempos e espaços iguais, independentemente da vontade das pessoas. Pode-se dizer que há uma inconstância no cotidiano da escola, pois não vejo uma simetria no que diz respeito a tempos, à localização e organização espacial, ao desenvolvimento das atividades didáticas e das próprias pessoas que participam da escola. Algumas apresentam assiduidade integral e outras a freqüentam irregularmente, todas respeitando suas vontades. Essa intermitência, que por vezes causa incompreensóes, especialmente na relação com os gestores da política pública de educação escolar, mostra também um desempenho de equilíbrio e beleza, que conforma um conjunto harmônico, marcado ao mesmo tempo pela variação, pela discrepância entre uma e outra situação escolar e pela continuidade, que confere regularidade à concorrência de acontecimentos que está se inserindo no interior de cada aldeia.

Tempo do encantamento! Poderia assim dizer sobre a duração de uma aula nas escolas Anhetenguá e Karai Arandu, nas aldeias Guarani 
Educação escolar indígena: um modo próprio de recriar a escola nas aldeias Guarani

da Lomba do Pinheiro e do Cantagalo, respectivamente. Percebo que, enquanto há encanto, estão, professor e alunos, envolvidos em atividades que fazem sentido naquele momento: terminado o envolvimento, termina a aula. Alguns registros do Diário de Campo revelam como, na prática, ocorre essa duração:

Aos poucos as crianças se dispersam e sinto que acabou o encanto. Saem da sala de aula discretamente, não há tema de casa, nem cobranças por parte do professor, confirmando uma fala do Santiago, em que dizia que a criança Guarani fica na escola enquanto tiver vontade. (25 mar. 2004).

Do mesmo modo, cada criança faz sua atividade em seu tempo, pois não há, por parte do professor, nenhuma imposição de regras temporais, como nos habituamos em nossas escolas, cujas atividades são planejadas para determinado período de execução, tempo esse explicitado e treinado junto aos alunos e que, por vezes, funciona como ameaça: "tem mais dez minutos para concluir o trabalho!".

Também o momento que entendem como recreio não é determinado mecanicamente pelo relógio e ocorre através do anúncio do professor, em geral ao final de uma atividade. Há, nesse intervalo, um misto da aula e da vida ordinária na aldeia, especialmente considerando a suavidade de falas e movimentos, o que, longe de deixá-los quietos e acabrunhados, insere-se nas alegres brincadeiras, sempre em grupos.

Por sua vez, o início das atividades escolares é marcado pela chegada do professor, que, ao passar pelo pátio da aldeia, anuncia que a aula está prestes a começar. Assim, as crianças vão-se aproximando, algumas de cabelo molhado, outras ainda a se pentear, bem apresentáveis, um cuidado que observo em todas as pessoas Guarani, quando participam de uma atividade que foge à rotina ou que vai ao encontro de um grupo maior que a família nuclear. No entanto, as crianças que chegam depois se incorporam ao grupo sem constrangimento e, com a discrição que lhes é própria, entram na sala, apanham o seu material escolar, tomam um lugar e se integram às atividades. "Parece que a aula começa e termina em si, sem maiores envolvimentos externos", registro no Diário de Campo (30 mar. 2004). O tempo vivido, sentido internamente, sobrepõe-se ao relógio. O ritmo da aula é o ritmo do coração.

Nas aldeias Guarani do Cantagalo e da Lomba do Pinheiro, predomina uma idéia que tenta organizar a prática escolar separando aula 
das crianças e aula dos adultos. Observando a organização da aldeia e a escola funcionando de fato, percebo que essa separação não ocorre com perfeição, embora mostrem iniciativas concretas. A melhor expressão que encontrei para dizer das pessoas que circulam na aula é "uma mistura de crianças e adultos”. É assim no cotidiano da aldeia; é assim na escola. "É difícil, na aldeia, deparar com um ambiente sem mistura de crianças, jovens e adultos. Nesses momentos, penso e me indago: Como será a escola?" (Diário de Campo, 4 nov. 2003). Contudo, a resposta que encontro reflete a admiração diante de uma aula que, a princípio, era de adultos, mas se constitui num espaço onde circulam crianças que escrevem no quadro, anotam, escutam, atentas, o que está sendo feito.

A maneira usual de aprenderem uns com os outros, especialmente através de um olhar atento e curioso dos menores para o fazer dos maiores, transpóe-se para a escola, conquanto a preocupação dos professores em organizar turmas de crianças maiores e crianças menores, afinal, a classificação por idade é uma marca forte da escola moderna e extrapola o costume de práticas locais. Nesse sentido, sobressaem também os momentos específicos e adequados para a aprendizagem de cada faixa etária, prática que coexiste à convivência habitual de pessoas de diferentes idades. As escolas que observei são, no nosso dizer, multisseriadas e, assim como convivem pessoas de diferentes idades, também convivem diferentes níveis de conhecimento: algumas lêem com fluência e conhecem as letras para articular a escrita de muitas palavras, enquanto outras estão realizando o primeiro contato com as letras.

Observo que a organização do espaço escolar é orientada por duas compreensôes e se traduzem na estética da sala de aula: uma que representa a vontade dos professores e de algumas pessoas da aldeia mais afetas à escola, tendo como parâmetro a organização escolar canônica, dos alunos sentados em fileira, todos dirigindo seus olhares para o quadro ou para o professor, que, igualmente, se posta na frente de todos; e a que segue sutilmente o que está posto no modo tradicional de vida Guarani ou o que as condições concretas impõem ao fazer escolar, como fileiras, círculos e agrupamentos variados. Por outro lado, a reflexão constante sobre o prédio escolar tem conferido movimento visível à idéia de como o concebem. Percebia, nas primeiras conversas sobre escola na aldeia, que as pessoas Guarani tratavam com equivalência escola e prédio escolar. 
Na Lomba do Pinheiro, há uma explícita resistência na decisão por um prédio específico para a escola, pois, para eles, não há a necessidade de um lugar fixo para aprender. $\mathrm{Na}$ reunião que decidia pela escola na aldeia, Alberto traduziu para o português as reflexôes iniciais das pessoas aí presentes: "a aula não precisa ter prédio, não precisa estar embaixo de um teto. Em qualquer lugar, na sombra de uma árvore, pode surgir a qualquer momento, não precisa de preparação”. $\mathrm{Na}$ aldeia do Cantagalo, a preocupação com o espaço escolar também passa intensamente pela reflexão dos professores e das lideranças, porém apresenta um sentido inverso ao verificado na outra aldeia, visto que insistem junto aos órgãos governamentais para a construção do prédio escolar há quatro anos.

No interior da escola, a organização espacial dos alunos também segue essa flexibilidade, sendo que a organização canônica de escola, das crianças uma atrás da outra, é uma referência, mas, na prática, o que mais ocorre é o agrupamento espontâneo em torno das mesas já colocadas, em círculo e também no modo de fileiras, seguindo a formação em que se dispóem para as danças tradicionais na $O p y$.

A oralização, presente nas atividades áulicas, com repetições sonoras fortes e vibrantes que o professor implementa no trabalho com as letras, também é indício da influência da tradição nas práticas escolares. $\mathrm{O}$ modo como o professor se dirige a cada criança distancia-se da simultaneidade das aulas que a escola convencional realiza em suas turmas, em que pese a presença de diferenças individuais. Assim como são atendidos na individualidade, perpassa a aula um constante fazer juntos, olhar para o caderno do outro, desenhar no desenho do irmão, ajudar os pequenos a desenhar as letras ou repetir a pronúncia de uma palavra em português, até que outro a aprenda. São situações que ecoam na sala de aula um modo de viver na aldeia, em que as crianças andam em grupo, em que os menores acompanham e observam atentamente os maiores, repetindo e tentando imitar seus gestos.

Dispor o olhar para ver a sala de aula nos pequenos atos que a tornam diferenciada, em seu momento mais íntimo, evidencia o movimento de uma escola "se fazendo" na aldeia Guarani e são esses potentes pequenos atos que compõem, com as falas individuais e coletivas dos Guarani, os seminários que reúnem suas lideranças, pesquisadores das universidades, instituiçôes apoiadoras e gestores das políticas públicas 
que se constituem as políticas públicas de educação escolar indígena. Desde 1991, a Secretaria de Estado da Educação é responsável legal pela gestão da educação escolar indígena no Rio Grande do Sul, e é apenas no limiar do século XXI que as ações mais concretas em relação às escolas Guarani, em sua especificidade, começam a aparecer. Convém considerar que nem sempre é explicitado, por parte dos gestores das políticas públicas, uma intenção em considerar os povos indígenas como atores que também definem as práticas educativas em suas escolas, fazendo predominar uma grande incompreensão, que se manifesta tanto nas aldeias como na própria Secretaria de Educação. Porém, é importante perscrutar o eco desse movimento que se dá no encontro de duas cosmologias, e como é traduzido nas leis e nas ações governamentais que materializam as políticas públicas, assim como a forma de se concretizar num fazer escolar diferenciado nas aldeias.

O olhar que localiza os Guarani também como protagonistas da política pública é o olhar que foge da unilateralidade e, mesmo no silêncio, reconhece a potência de um povo que sobrevive aos mais refinados atos de destruição, mantendo suas crenças e seu modo de ser, modificando-as de acordo com as solicitações do presente, porém, coerentes com uma cosmologia que se transforma, mas continua Guarani. Reconheço nesse povo uma força sutil de resistência que, talvez, o olhar da política tradicional traduza como conformidade. É o que Maffesoli (2002) denomina "potência", que tem que ser sentida, porque é "tátil”, constituída por uma multiplicidade de açóes que incluem silêncios e passividades e que fazem perdurar o modo de ser Guarani.

Conquanto a força homogeneizadora da escola e a marca da cosmologia ocidental moderna que a engendrou e que não pode mascarar sua intrusão no modo de vida tradicional em uma aldeia, fica igualmente evidenciado que essa escola se faz diferente quando inserida no Guarani Reko, quando é apropriada e ressignificada pelas pessoas que a fazem na aldeia. São pequenos indícios de uma escola que segue outras determinaçóes e que tem relação forte com o solo e com as pessoas que a engendram, que a fazem no seu estar aí. Necessitam e buscam a escola. Porém, é nos pequenos gestos cotidianos, sustentados pelas características de sua educação tradicional - a curiosidade, a observação, a imitação e o respeito, entre outros atributos responsáveis pela confecção da pessoa Guarani -, que se apropriam da escola, tornando-a sua. 
Educação escolar indígena: um modo próprio de recriar a escola nas aldeias Guarani

\section{Glossário $^{3}$}

Anhetenguá: significa liberdade, a verdadeira sabedoria Guarani que permite viver a liberdade. É a palavra que resume a filosofia, as verdadeiras palavras Guarani.

Arandu: saber, conhecimento, sabedoria. Significa sentir o tempo, fazer o tempo agir na pessoa.

Jataity: nome da aldeia do Cantagalo, assim denominada pela abundância de butiá ou "butiazeiro", como dizem os moradores da aldeia quando perguntados pelo significado do nome de sua Tekoá.

Karai: Chefe espiritual responsável pelo cuidado na aldeia Guarani.

Kyringue: crianças, criançada.

Mbyá: parcialidade ou rama Guarani.

Nhande Reko: "Nosso modo de ser". O modo de ser Guarani, sua cultura, também denominada Guarani Reko ou Mbyá Reko, referindo-se a essa parcialidade.

Nhembo'e: Escola, estudo. É a expressão usada para referir a educação escolar e as práticas decorrentes dela.

$O p y$ : casa tradicional de reza. Lugar sagrado do "estar juntos" espacial e temporal do povo Guarani.

Reko: o modo de ser Guarani, a sua cultura.

Tekoá: lugar bom para o Guarani viver, para construir a aldeia Guarani.

Recebido em outubro de 2006 e aprovado em março de 2007.

\section{Notas}

1. Apropriação é uma palavra forte para a pesquisa que realizo nas escolas das aldeias, pois traduz o movimento de tornar algo próprio, adequado às necessidades de quem se apropria, mesmo que na origem esse bem não lhe pertença. Compreendo que, através dos sentidos próprios que conferem à escola na aldeia, os Guarani se apropriam dela, tornando-a também sua. Certeau (1994, p. 261) diz que apropriação é o fato de um determinado setor da sociedade tomar para si uma prática social tida como das elites e recriá-la. Significa, segundo o autor, tornar o bem assimilado "semelhante ao que se é, fazê-lo próprio, apropriar-se ou reapropriar-se dele". 
2. As duas aldeias situam-se próximo à UfRgs: Lomba do Pinheiro, no município de Porto Alegre, a uma distância de $24 \mathrm{~km}$ do campus central; Cantagalo, na divisa dos municípios de Porto Alegre e Viamão, dista $42 \mathrm{~km}$ do campus central da Universidade.

3. Os termos usados aqui no idioma indígena tiveram o significado construído após a leitura de estudiosos dos Guarani e, principalmente, na interlocução com as pessoas das aldeias.

\section{Referências bibliográficas}

BALANDIER, G. A desordem: elogio ao movimento. Rio de Janeiro: Bertrand Brasil, 1997.

BERGAMASCHI, M.A. Diário de campo. Porto Alegre: [s.n.], 20032005.

BERGAMASCHI, M.A. Nembo'e. Enquanto o encanto permanece! Processos e práticas de escolarização nas aldeias Guarani. 2005. 270 f. Tese (Doutorado) - Faculdade de Educação, Universidade Federal do Rio Grande do Sul, Porto Alegre.

CERTEAU, M. A invenção do cotidiano 1: artes de fazer. 3. ed. Petrópolis: Vozes, 1994.

DORNELES. M.A. Lo publico y lo popular en el ambito racionalizador del orden pedagogico moderno. 1996. 300f. Tese (Doutorado). Universidad Católica de Córdoba, Córdoba (Argentina).

ELIAS, N. A sociedade dos indivíduos. Rio de Janeiro: Zahar, 1994.

JACUPÉ. K.W. Tupã Tenonde: a criação do universo, da terra e do homem segundo a tradição oral Guarani. São Paulo: Peirópolis, 2001.

LARICQ, M. Ipytuma: construcción de la persona entre los MbyaGuaraní. Missiones: Editorial Universitaria, 1993.

MAFFESOLI, M. O tempo das tribos: o declínio do individualismo nas sociedades de massa. 3. ed. Rio de Janeiro: Forense, 2002.

SILVA, A.L. Educação para a tolerância e povos indígenas no Brasil. In. Grupioni, L.D.B; Vidal, L; Fischmann, R. (Org.). Povos indigenas e tolerância: construindo práticas de respeito e solidariedade. São Paulo: EDUSP, 2001. p. $99-131$. 